$$
\begin{aligned}
& \text { SF } 265 \\
& A 6 \\
& 1915
\end{aligned}
$$



SF 265

. A6

\title{
1915
}

Copy 1

\section{Test Rules}

AND

Register of Merit Rules

\author{
American \\ Jersey Cattle Club
}

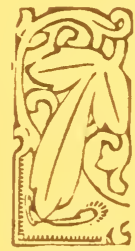

Issued by the Club

May 4, I0I5 


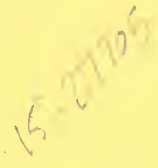

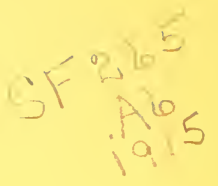

$\therefore \vdots$

$\therefore$

(C) 


\section{CONTENTS}

PAGE

Authenticated Fat Tests................. 5

Confirmed Butter Tests................... 8

Experiment Stations, Fat Tests Made at........ 6

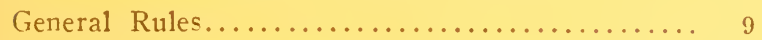

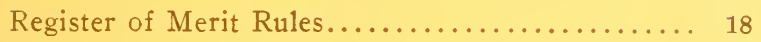

Rules Governing Test Supervisors............ 14 



\section{Test Rules}

Adopted January 29, 1913. Amended January 28 and April 15, 1914, and May 4, I9I5

\section{AUTHENTICATED FAT TESTS}

These are tests supervised by a representative of a State, Provincial, or national experiment station or agricultural college, who certifies as to the weight of the milk, and the percentage of fat it contains, on the days on which the cow is under official test.

\section{Year's Tests}

1. Year's tests cover a period of not more than 365 consecutive days, and must be authenticated by applying the Babcock test to a sample of the milk of every milking during two consecutive days in each month.

\section{Required Yield}

2. If the test is commenced the day the cow is two years old, or previous to that day, she must produce, within one year from the date the test begins, 250.5 pounds butter-fat. For each day the cow is over two years old at the beginning of her year's test, the amount of butter-fat she must produce in the year is fixed by adding 0.1 (one-tenth) of a pound for each such day to the 250.5 pounds required when two years old. This ratio of increase applies until the cow is five years old at the beginning of her test, when the required amount will have reached 360 
pounds, which will be the amount of butter-fat required of all cows five years old or over. These standards are based upon one complete year's record from the time of beginning, regardless of any time which may be lost by being dry or calving during that period.

The production of butter-fat in each month is to be computed from the results obtained by the official application of the Babcock test.

\section{Seven, Fourteen and Thirty Days' Tests}

3. In the case of tests for seven, fourteen or thirty days, the Babcock method must be applied to a sample of the milk of every milking during the test, and the milk of every milking must be weighed.

No record will be accepted of a test of less than twelve pounds of butter-fat in seven consecutive days.

No record will be accepted of a test for a period of thirty consecutive days, or any shorter period down to seven days, unless the butter-fat amounts, on the average, to one and seven-tenths pounds per day.

No test for seven, fourteen or thirty days will be accepted unless same has been begun at least twenty-one days after the cow has freshened.

\section{Fat Tests Made at Experiment Stations}

In cases where cows are owned by or have been turned over to a State experiment station or agricultural college to be tested for one year, the animals remaining continuously at the station and under the exclusive care and control of the station officials during the entire period of the test, such tests will be accepted as authenticated, 
and the cows will be eligible to the Register of Merit, provided:

First.-That the yield of butter-fat meets the requirements as to yield stated in these rules; and

Second.-That the report of the test is signed and sworn to by the supervisor and countersigned by the director or other qualified official of the station, and that it has been conducted either according to the regular rules or in accordance with the following method:

1. The milk of each milking during the test shall be weighed and the weight recorded.

2. The milk of each milking shall be carefully mixed immediately after milking, and an aliquot sample comprising as many cubic centimeters of milk as the number of pounds of milk in the milking shall be taken, placed in a composite sample bottle and carefully preserved.

3. Each week composite samples representing the milk of the entire week shall be tested for fat, and the total fat in the week's milk shall be computed from the percentage of fat thus shown.

4. In any fraction of a week, the milk of which is included in a test record, the fat percentage shall be ascertained in the same way as in a full week; and the fat production to be credited to the cow shall be the total of the fat of all the weeks and fractions of a week embraced by the test.

5. At the end of the test the experiment station or agricultural college shall report the test fully to the Club on a form furnished for the purpose. certifying to the statements made. 


\section{CONFIRMED BUTTER TESTS}

\section{Churn Tests}

1. All confirmed tests shall be churn tests, confirmed by the Babcock, as hereinafter provided.

No test for seven, fourteen or thirty days will be accepted unless same has been begun at least twenty-one days after the cow has freshened.

\section{Babcock Tests}

2. In making confirmed tests, the supervisor shall apply the Babcock test to the milk every day during the period for which such test is made, making a separate test of each milking; except in the case of confirmed tests for yearly periods, when he shall apply the test to each milking during two consecutive days in each month. If such application of the Babcock test practically confirms the test made by the churn, the "confirmed test" may be accepted by the Club.

\section{Analysis of Butter}

3. Every confirmed test shall be accompanied by a chemical analysis of a sample of the butter made at each churning; and no test shall be accepted wherein the butter averages less than eighty per cent. of fat.

\section{Computing the Butter}

4. The churned butter made in confirmed tests shall be computed on the basis of eighty-five per cent. butter-fat, thus reducing butter containing varying proportions of butter-fat to a common basis for purposes of comparison. 


\section{Production Required}

5. No record will be accepted of a confirmed test for a shorter period than seven days, and no record will be accepted for a period of thirty consecutive days or any shorter period unless the churned butter, analyzing eighty per cent. fat, amounts, on the average, to two pounds per day.

No record will be accepted of a confirmed test for a period of one year unless the churned butter, analyzing eighty per cent. fat, is confirmed by Babcock tests indicating yields of butter-fat at the various ages in accordance with the provisions for fat yield in authenticated fat tests.

Note.-In confirmed tests the supervisor makes report, on a form furnished for the purpose, of the weights of milk and fat, and calculates the equivalent of the fat yield in eighty-five per cent. butter. The owner of the cow makes report to the Club, on a separate form, of the yield of milk and churned butter, feed given, weight of cow and date of last calving. The reports of the person doing the milking and churning must be sworn to. The butter is computed by the Club on the basis of eighty-five per cent. fat-that is, the cow is credited with the weight of eighty-five per cent. butter that the actual churned butter is equivalent to.

\section{GENERAL RULES}

\section{Application for Test}

1. No test shall be accepted for record unless the cow tested has been admitted to the Herd Register of the American Jersey Cattle Club. Before a test is commenced application shall be made to the Club, ten days' notice being given the Secretary in order that arrangements for a supervisor may be made, the name and Herd Register number of the cow to be tested being also stated. 


\section{Test Supervisors}

2. No one is competent under these rules to supervise tests unless he is appointed or recommended, and his reports are countersigned by the director, dairy husbandman, or other proper authority of a State experiment station or agricultural college, and no one can supervise tests of cattle over which he has charge or in which he has any pecuniary interest.

Institutions sending out supervisors are requested to change them whenever practicable, so that the same man may not go continuously to any particular herd.

Under no circumstances shall any payment or gratuity to the supervisor be made by or permitted from the owner of the cow or any one interested in her, and any violation hereof shall invalidate the test.

The owner of the cows under test must provide for conveying supervisors to and from railroad station on line of travel.

The reports of supervisors shall be retained permanently on file at the office of the Club.

\section{Starting Tests}

3. Tests may be begun at any date during the lactation period, to continue for not more than 365 consecutive days, including any time the cow may be dry during this period, but the milk record must not begin earlier than the fourth day after calving, the day on which the calf is dropped being counted as the first day.

\section{Reporting Milk Yield}

4. The milk of every milking during the continuance of a test must be weighed and the 
weights reported to the Club in detail, signed by the manager of the cow, on forms provided for the purpose.

The month's milk record in year's tests shall be reported to the Club within thirty days after the close of each monthly period, and the test data for the entire year shall be certified to at the conclusion of the test, in the form of an affidavit by the manager of the cow.

The owner's barn sheets with the original milk records of tests should be preserved by owners of cows until the Club has either accepted or rejected the tests, and shall be forwarded to the Club for inspection if required.

\section{Feed and Care}

5. The feed and care of cows under test are under the control and direction of the owner. As far as possible, the weights and quantities as well as kinds of feed given the cow should be stated. No condiments, condition powders, or drugs are permitted to be given the cow, except remedies in case of sickness, when statement of that given is required.

\section{Receptacles for Samples}

6. Owners of cows must provide suitable glass receptacles for samples, and also a box or closet in which same may be kept securely under lock and key.

\section{Retesting}

7. If the milk averages in any two days below 3.5 per cent. butter-fat, the owner may have a retest made, at his own expense, if he so desires; but notice of such retesting must be given the Club within fifteen days. The Club will 
pay the entire cost of all other retesting required by the rules. All data secured in cases of retesting shall be reported to the Club, and all or any of such data may be used in determining the average percentage of fat for the month in which retesting is called for, the Club reserving the right of disregarding the results of any test made when a cow is in a decidedly abnormal condition.

\section{Omission of Monthly Test}

8. In the case of cows freshening after, or finishing their tests before, any regular visit of the supervisor, the results of the tests made at his succeeding visit, in the first case, and of the tests made at his previous visit, in the latter, shall be used in determining the fat to be credited for such portions of monthly periods.

In cases where, in any monthly period, no tests have been made owing to unavoidable circumstances, the institution supervising the test shall make explanation to the Club of the circumstances, and the Secretary may authorize the average percentage of fat shown by the tests of the preceding and succeeding months to be used in determining the fat to be credited; provided that, in his opinion, good and sufficient cause has been shown for the omission.

\section{Tests Made at Experiment Stations}

9. When a test is made by any State, Provincial, or national experiment station or agricultural college, in conformity with these rules, and such test is certified to by the proper officer of such station or college, the same may be accepted by the Club. The officials of such stations and colleges are qualified under these rules to supervise the tests of cows belonging to the institutions 
with which they are officially connected; and a student is qualified to test the cows belonging to the college where he studies, under the supervision of the officials aforesaid.

\section{Rejection of Tests}

10. All tests shall be made and carried on as provided in the rules of the Club, but the Executive Committee shall at all times have the power to reject any proffered test on objection being made and evidence submitted; and the Executive Committee shall be the exclusive judges of the sufficiency of any objection and the evidence submitted in support thereof. The committee shall also have the power to expunge from the records any test shown to be erroneous or fraudulent.

\section{Expenses of Testing}

11. The owner of the cows under test shall pay all the expenses of testing. The agricultural college or experiment station sending out the supervisor shall collect from the owner of the cows the cost of this supervision and pay the supervisor, the Club guaranteeing the station or college against loss if the owner fails to pay in any particular month; but in such cases the college shall stop the tests.

In cases where the above plan cannot be carried out by a station, the Club shall charge the owner with the expense and pay the supervisor. Should the owner fail to reimburse the Club each month within thirty days after bill is rendered him, the test shall be stopped. No test shall be published unless all bills for testing have been met by the owner of the cow. 


\section{Blank Forms}

12. Blanks for use of the supervisors and the owners of cows will be furnished by the Secretary of the Club upon request.

13. All Register of Merit records are published free of charge; but no test shall be published, or furnished for publication, until the animal making said test is entered in the Register of Merit.

\section{Rules Governing Supervisors of Tests}

Identity and Condition of Cow.-1. The supervisor should as far as possible satisfy himself as to the identity of the cow under test; he should note upon his report form any sickness of a cow or other condition likely to affect the reliability of a test; he should also report any irregularity or suspicious occurrence, and in all ways endeavor to conduct a fair test.

Rules Must be Followed.-2. The supervisor is not at liberty to decide as to which stipulations contained herein are essential and which are not, but is required to observe these directions in all details.

Secing Cow Milked.-3. A supervisor shall be present at and throughout each and every milking during the entire test period of two days in each month during the test year. In case of tests for shorter periods than one year he shall be present at each and every milking during the continuance of the test.

Under no circumstances shall more than one cow undergoing test be milked at the same time, and the supervisor must in every case be in position to observe the milker during the whole milking.

Weighing Milk.-4. The supervisor shall assure himself as to the accuracy of the scales used, and they should be graduated to pounds and tenths. He shall weigh the empty milk-pail before each milking, and after the milking he shall satisfy himself that the pail contains nothing but the milk drawn from the cow under test; he shall take charge of the pail and its contents, weigh the milk given at each milking immediately after it is milked, and record the exact weight of the milk on the blank form provided for that purpose. 
Sampling Milk.-5. The supervisor shall take a sample of the milk of each milking for determination of butter-fat immediately upon the weighing of the milk, being careful that the milk is thoroughly mixed by pouring from one pail to another, or by means of a dipper, before taking the sample, to insure that it is a fair sample of the whole. Such samples must always be securely retained until tested under the absolute control of the supervisor, and, when not in his actual possession, under lock and key, if necessary, and the testing shall be proceeded with as soon as convenient after the samples have cooled to ordinary room temperature.

Applying the Babcock Test.-6. The supervisor shall apply the Babcock test to the milk of every milking during the test period of two days in each month during the test year, making a separate test of each milking. In the case of tests for shorter periods than one year he shall make a separate test of each milking during the continuance of the test. He shall determine the percentage of butter-fat in each sample, placing the required amount of milk from the sample in at least two test bottles for that purpose, recording the readings of both bottles. Should the reading of such butter-fat show a greater variation than two-tenths of one per cent. between two bottles, the supervisor shall make another determination of the percentage of butter-fat by two test bottles to correct the previous one. If the variations between the two determinations is two-tenths or less of one per cent., the supervisor shall take the mean between the two decimal fractions as the percentage of butter-fat upon which he shall calculate the total fat in such milk. Readings of test bottles should be made when at a temperature of about 130 degrees $F$. The supervisor shall record in ink the total amount of butter-fat shown by the Babcock test to have been contained in the milk of each milking.

Determining Fat Percentage.-7. The average percentage of fat shall be determined by dividing the total yield of fat shown by the tests by the total amount of the milk tested. Fat percentages must be carried out to at least three decimal degrees.

Retesting.-8. (a) If in the supervision of any test the supervisor finds that the yield of fat in any two days after the first month of the test period is in excess of the appropriate amount specified in the following table, he shall inform at once the authority by which he was 
appointed, so that a retest for two days by another test supervisor shall be made within ten days after the termination of the first test:

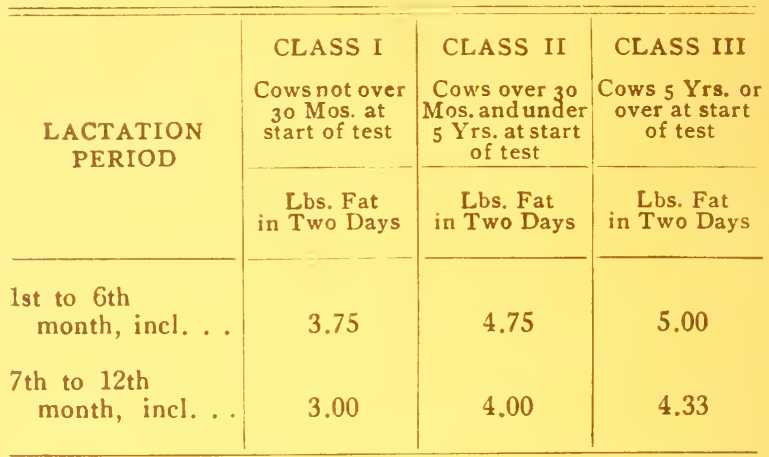

(b) If in the supervision of any test the supervisor finds that the milk averages for the two days above seven per cent. butter-fat when it averages thirty pounds or over per day, or above eight per cent. when it averages fifteen pounds or over per day, there shall be a retest as stipulated in Section $8(a)$.

Lost Milk and Lost Samples.-9. If any or all of the milk of a milking is accidentally lost before weighing, the weight of that which has been lost is to be supplied by taking the weight of the corresponding milking in the test period; and if the sample from any milking is accidentally lost before testing, the missing test is to be obtained by taking the results of the tests made of the corresponding milking during the test. For example, if an evening milking is involved, the preceding or succeeding evening milking shall be used. It must be stated on the report form that any data thus obtained are estimated.

Reports of Supervisors.-10. The supervisor shall sign his reports, and shall send them promptly, for checking and indorsement, to the agricultural college, State experiment station, or other institution under whose authority he acts, accompanied by a memorandum of his expenses.

A preliminary report shall be mailed by the supervisor immediately after the test direct from the farm to the Secretary of the Club. 


\section{Special Rules for Supervisors of Confirmed Butter Tests}

Computing Butter.-In confirmed butter tests butter shall be computed on the basis of eighty-five per cent. butter-fat.

Analysis of Butter.-Every confirmed butter test shall be accompanied by a chemical analysis of a sample of the butter made at each churning. It shall, therefore, be the duty of the supervisor to procure samples of butter from each churning made while he is testing the cow, and to send the same to, or as directed by, the Club, securely sealed, for the purpose of analysis. Should a churning not have been made during the time the supervisor is taking the Babcock test of the milk of the cow, he shall remain at the expense of the owner until one churning has been made, so that he can procure a sample. The supervisor will be careful to see that the butter he sends as a sample is taken from each churning, should there be more than one, and that the same remains securely in his possession from the time such sample is taken until sent to, or as directed by, the Club. The supervisor will instruct the owner to send for analysis a sample of the butter of any churning made after he leaves.

Samples of Skim-Milk and Buttermilk.-In confirmed butter tests it is very desirable, though not compulsory, that the supervisor procure a sample of the skim-milk after each skimming, and also of the buttermilk, and ascertain the percentage of butter-fat that was lost by skimming and churning and report the same. 


\section{Register of Merit Rules}

With the purpose of raising to a still higher standard the average excellence of the Jersey cow, and of securing an additional authoritative and permanent record to which reference can be made in the selection of breeding animals, the American Jersey Cattle Club has adopted the following rules for the establishment of a Register of Merit, to which shall be eligible meritorious bulls and cows, judged by the standards of progeny and dairy performance. All animals previously entered in the Herd Register of the American Jersey Cattle Club may be recorded in the Register of Merit when they comply with one or more of the following conditions:

Basis of Entry of Cozus.-No application for entry in the Register of Merit based upon the production of butter-fat shall be entertained unless accompanied with proof of compliance with the rules for making authenticated fat tests, and no application for entry in said Register based upon the production of butter shall be entertained unless accompanied with proof of compliance with the rules for making confirmed butter tests.

Class AA.-A cow shall be entitled to entry in Class AA after the production, in one year, of the amount of butter or butter-fat specified in the test rules, provided that said application shall be accompanied with proof by the affidavit of the manager of the cow (attested by the cer- 
tificate of the owner thereof, where the owner is not the manager) that said cow has either dropped a living calf during the period covered by said test and not less than 155 days after the beginning thereof, or has dropped a living calf within 125 days after the completion of said test.

Cows already entered in Class A may, upon application therefor, be transferred to Class AA, upon presentation of the additional proof above specified as requisite to entitle animals to entry in said class.

Class A.-A cow shall be entitled to entry in Class $\mathrm{A}$ after the production, in one year, of the amount of butter or butter-fat specified in the test rules.

Class B.-A cow shall be entitled to entry in Class $B$ after the production in seven days of the amount of butter or butter-fat specified in the test rules.

Re-entry.-Cows which have already been entered in the Register of Merit, upon meeting the requirements in another test, will be re-entered under the same number, and certificate issued free of charge.

Bulls.-A bull shall be entitled to entry in said Register of Merit after three of his daughters from as many different dams have been entered therein on year's authenticated butter-fat or butter records. When a bull becomes eligible to the Register of Merit, he shall be entered therein by the Secretary, without application being made, and free of charge.

Certificates of Entry.-The Secretary shall issue certificates of entry of all animals admitted to the Register of Merit. The application, and 
all other evidence on which he makes such entry, shall be kept on file by him and be subject to examination by any member of the American Jersey Cattle Club.

Fees.-The fee for entering a cow in the Register of Merit and issuing a certificate, which shall set forth the record made by the animal, shall be $\$ 2$. This fee must be sent with the final report of a test by the owner [Form No. 62, which also constitutes the application for entry of the cow in the Register of Merit], the amount of fee to be returned if cow does not qualify, or placed to the remitter's credit, as directed. If a certificate of entry of a bull is desired, the same may be obtained by paying a fee of $\$ 2$.

Supervision and Direction.-The Register of Merit shall be under the general supervision and direction of the Executive Committee.

The Secretary of the Club is authorized, under direction of the Executive Committee, to prepare said Register, and to publish the blank forms and circulars needed in carrying this system into effect. 



\section{LIBRARY OF CONGRESS}

|||||||||||||||||||||||||||||||||||||||||||||||

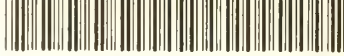

\section{2}

Hollinger Corp. $\mathrm{pH} 8.5$ 